\title{
Effectiveness of Oral Tests in Improving Learners' Mathematical Performance
}

\author{
Ahmad Hedayatpanah Shaldehi
}

\begin{abstract}
The main purpose of this paper is, the effect of guided oral questions in mathematics lessons on evaluation formative testing in Increase academic achievement. The sample of the Research consisted of two 23-person classes from computer students at the University of Dr. Moien Rasht. Both classes took pre-test, with a common question from the semester's lessons. Randomly, Class A was selected as the control, and Class B was selected as the experiment. In Class A, after 6 weeks of teaching, evaluation formative the classical test was formally written (paper-and-pencil) .Group B students, with the same content of Class A teaching, received group Oral (participatory) instead of, formative tests. Group members were selected based on formula, According to the attention, pre-test scores value, and other Indicators. At the end of the semester, both classes were aggregated with the same question, and the scores of both classes were analyzed by descriptive and inferential statistics, $t$ and $E S$ .Statistical analysis showed that learning rate increased in both control and experimental groups. But in cumulative Evaluation, the mean scores of the experimental group were higher than the Average scores of the control group. While in the pre-test, the control group scores were higher than the experimental group. The area under the corresponding curve, ES $=.96$, is / 831. That is, the area under the curve corresponding to the test group members, on whom the developmental test was orally administered, their mathematics lesson scores were83.15 higher than the control group.
\end{abstract}

Keywords: Effect size, Oral, Participatory, Formative Evaluation, Mathematical, Cumulative Evaluation.

\section{INTRODUCTION}

Today it cannot be accepted that mathematics, even pre-school mathematics, is taught by uninformed people, without regard to the principles and principles of mathematical education.

Teaching and learning, and the assessment of learners' mathematical behavior, are complex processes in which teachers and educators are directly linked. (Alamolhodaei . 2002).

In fact, progress tests play a very important role in different types of curricula. An achievement test is a regular measure of student learning. Although, in these tests, the measurement of learning outcomes is emphasized, it should not be confined to merely completing one teaching session,

Manuscript received on 22 September 2021 | Revised Manuscript received on 03 October 2021 | Manuscript Accepted on 15 October 2021 | Manuscript published on 30 October 2021. * Correspondence Author

Ahmad Hedayatpanah Shaldehi*, Department of mathematics and Computer, Faculty of Moin Rasht Branch, Technical and Vocational University (TVU), Guilin, Iran Email: Ahmad.hedayatpanah@gmail.com

(c) The Authors. Published by Lattice Science Publication (LSP). This is an open access article under the CC-BY-NC-ND license (http://creativecommons.org/licenses/by-nc-nd/4.0/)

the final teaching measurement being just one type of test. It is essential that examiners, as an integral part of the teaching process, be required to fulfill all the capabilities of the academic achievement test. The teacher makes many decisions from the beginning to the end of the teaching. The teacher must make three sets of decisions with the help of these tests. 1- Decisions at the Beginning of Teaching (Referral Test) (Lotfabadi: 1996).

This is called preassessments, or pre-test. Here, the teacher must answer two questions before proceeding. A) Are the learners, skills and prerequisites of the new lesson already dominant (Seif: 2001)

Ready to measure student responds to these questions. (B) To what extent have students already learned the content of the intended learning in the teaching program? This question can be answered by measuring the student placement. (Lotfabadi: 1996)

In cumulative Evaluation that all students learn during a course. Its purpose is to give students a score, a judgment about themselves, a teacher's effectiveness, and a curriculum (Seif: 2001).

Due to the types of changes that occur in different areas of learning, there are at least five evaluation methods as follows: 1- Evaluation through observation 2- Evaluation by doing work 3- Evaluation through oral examination 4- Evaluation through Written Exam 5 - Combined Evaluation (Situational Examination).

\subsection{Evaluation through oral exam}

Evaluation is done through two tests. First, the student makes a permanent impact on his or her behavior, that is, he or she answers the questions posed in the class, and then the teacher scores the student based on the recorded answers. This is the same evaluation through a written test. Such as: entrance exams, written school assessment. In the second case, both questions are answered orally; the student confronts the teacher, and answers one of his questions, the discussion of which is the second position, the oral test. Verbal is a good tool for measuring information, the power of expression, the form of reasoning, the concentration of thoughts and the recognition of inner states, in terms of anxiety and fear. Such a test can be very useful and scientifically valid, provided that the questions are thoughtful, based on the educational content already provided. The results of this test are reliable when it is away from any comments, interference, personal exaggerations, etc. (Shaabani: 1993).

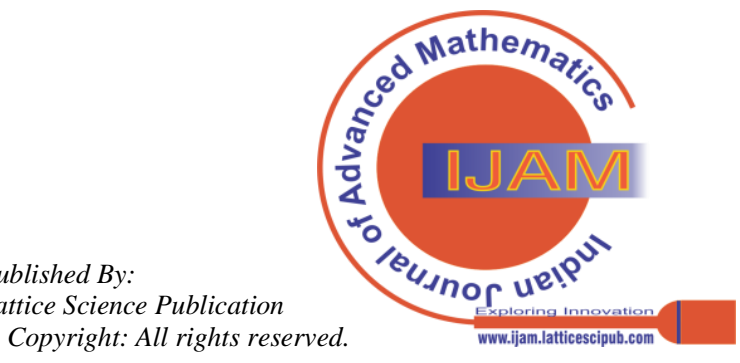


There has been some research on the benefits of oral questions, which corroborates this claim. Because, a study by Rashid, Yaghoubi, and Roghul Kordogord, entitled "A Comparative Study of the Impact of How a Classroom Oral Question Project on Learning a Mathematical Lesson to This Lesson" in 2015, Experimental, 25 Boys' Mathematics Classroom, First Year High School, Day Schools A boys' government was surveyed in five districts of Tehran, run by five teachers (each of 5 classes). Give students, then one of them, randomly selected to answer, and give them 5 seconds to answer, rate or Student retention was significantly higher than that in which the respondent was not selected before the question was asked, or the class verbal question was not used. The experimental groups were more than the control group. Also, there was a significant difference between students' interest in non-class questions and how to choose responsive to math lessons.

Also, a study titled "Investigating the Effectiveness of Education, Using Targeted Questions, on Mathematical Performance and Logical thinking." By Waezfar, Mohammadi Far and, Ngafi, on all male high school students in Dehdasht, who were studying in the high schools of the city in 2012-2013. The sample consisted of 62 patients in the two groups, 31 in the experimental group and 31 in the control group, respectively. The results of the analysis of covariance showed that the purposeful questioning training was able to significantly affect the components of comprehension, reflection, and critical reflection, but not the habit component alone. The teaching method, in mathematical practice, was able to make a significant difference in the experimental group compared to the control group. The findings of this study showed that targeted questioning training is effective on mathematical performance and its components of comprehension, reflection and critical reflection and reflective thinking. Therefore, using this method in high schools can improve mathematical performance and levels of reflective thinking. The category is briefly referred to as participatory methods. Because the collaborative approach is one of the most effective ways of learning or teaching,

The participatory method is the symbol and the practical model of the active method. It seems that activating students through participatory learning can be better done by the learners. This provides better opportunities for discussing and exchanging views with one another. These include effective ways to get students to talk, to use cooperative learning in the classroom, in classroom instruction. He points out that in small groups, students work together to achieve a common goal, and in addition to being responsible for their own learning, they feel responsible for their own learning. Collaborative learning means, by grouping students, based on similar abilities. On the contrary, the greater the heterogeneity of group members in terms of race, language, culture, intelligence, and academic achievement, the greater the effectiveness of the collaborative learning approach (Cohen 1994).

\subsection{Composition of the Participating Group Members:}

In terms of group composition, traits such as race, language, culture, emotional relationships, the degree of student agreement and academic progress, and the various views expressed, most of the views expressed were inconsistent. In terms of group size, the best group was named 4 people. But surveys in the UK show that most teachers prefer groups of 4 to 6 people (Dunn \& Bennett 1995).

1, 2 ,1. Participatory Learning Objectives in Mathematics:

1. Positive attitude towards mathematics

2. Confidence in abilities related to mathematical reasoning

3. Increasing interest and perseverance

4. Ability to accept failures and accept that this is not always an immediate solution to problems.

5. Acknowledging that not finding the right answer to solve mathematical problems is not a reason for one's self-sufficiency (Ronald quoted in David Johnson and Roger Johnson 1997).

In this research, the main purpose of the authors. The effect of Formative Evaluation on Participatory and Guided Oral Mathematics Lessons to Increase Academic Achievement.

\section{THE CONTENT AND METHOD}

\section{A. Questions:}

1. Has the new formative test method influenced math lesson scores?

2. In cumulative evaluation (end of semester) in the math lesson, in the new method, the experimental group performs better than the control group.

3. Are there any significant differences between the two groups after the procedure?

\section{B. Type of research}

The applied research method is experimental. Using pre-test and post-test, the experimental. Both groups were measured twice and control groups were administered 12 weeks in one semester.

\section{Statistical Sample:}

46 female students, in General Mathematics, Associate Degree in Computer Science, Dr. Moien Rasht, in 2 classes (23 students each) in the 2017 academic year. Done. Accomplished.

\section{Methods:}

After 35 years of teaching and research, the author decided to experiment with a new method. In this way, two classes of computer string $(A \& B)$ were selected at random. Some were absent during the first session. Therefore, the second teaching session outlined the goals of the one-semester line-by-line plan for each class and specified the timing schedule. Was taken.

In the Control class(A), they were instructed to perform the developmental (mid-term) test in written form only of the content, including concepts, definitions, examples, formulas and all other materials, as specified in the budget for the lesson. The test date was also specified.

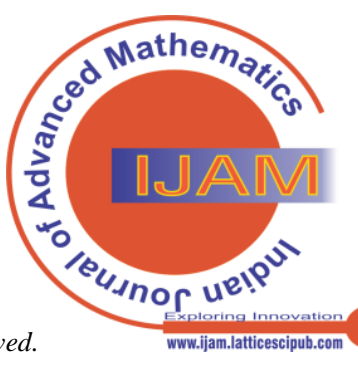


Experimental class (B) was divided into 6 groups based on pre-test scores. In each group, 4 people (very strong, strong, and moderate) were included. , It was mandated that the same group, with the same content as the same budget, be asked questions orally in accordance with the instructions below. Scores for both groups were 6 at the end of the semester.

\section{E. Instructions}

1. Experiment class B) was divided into 6 groups. For each group, one person was selected as the group leader (one very strong student with the highest score in the pre-test). Group members, 4 to 6 , are appropriate. Table (1) shows the pre-test scores.

2. Understanding and interacting with the pre-test scores and ethnicity, language, culture ...) 3 others (strong, moderate) joined each group.

3. Run from the sixth week of teaching to the following questions. (Because a good volume of headings had to be taught about $40 \%$ of the headings). Complete the questioning operation within 6 to 7 weeks.

4. During the semester, each group was asked only two times (group numbers were selected by lottery) (so everybody was asked within 6 weeks.)

5. One representative from each group was randomly selected and the questions asked were determined by the instructor, his / her pass, and the person's score for the whole group. The members of the group studied together in a participatory and group way during the semester. The mean scores obtained by the members in the verbal (formative) questions were identical for all. So their responsibility is the same.

6. How to answer; Representatives of the two groups were at the same time at the foot of the board. The two pre-selected question types were weighted by a draw. In this way, the first group was selected at random and had the right to choose one of two questions. The second question was for the next group.

7. Since each group of 3 questions is asked, the value of each question is 1 , with a maximum of 3 . The team representative only responds to the 3 questions previously asked by the instructor. After the end of the correction time, the class members will be observed.

8. Each 100-minute class session takes between 10-15 minutes ( 3 minutes for each question and 6 minutes for other preparations and correction). As a result, within 6 weeks 90 minutes or a maximum of 100 minutes is allocated, which equates to 90 minutes or 2 hours of mid-semester exam in Class A (control).

9. The class leaderboard is divided into two halves in the middle. The representative of the second group selects one section to his own satisfaction, the other group is assigned to the next group. They do not write questions on the blackboard, they only write answers.

10. Questions are designed in a clear and transparent way. Multilevel questions are avoided.

11. The content of the lesson for the first week (about $40 \%$ of the volume of the book).

12. If each class member (individually) scores $90 \%$ of the cumulative (end of term) grade. He is awarded a Full score of 20. Otherwise, the final score will be added to the midterm score.

\section{F. Exam Dates}

1. The end-of-semester exam date for both classes was officially formulated by the faculty.

2. Midterm Written Exam Date for Class A, Thirteen Week Training.

\section{FINDINGS}

\subsection{Class A. Performance (Control)}

Table (1) Status of Class A. Final Grades during Semester Paired Samples Statistics.

\begin{tabular}{|c|c|c|c|c|c|}
\hline \multirow[t]{2}{*}{ No } & \multirow{2}{*}{$\begin{array}{c}\text { Stands } \\
\text { Name } \\
\text { and } \\
\text { Surname }\end{array}$} & \multirow[t]{2}{*}{ code } & \multirow{2}{*}{$\begin{array}{c}\text { pre-test } \\
\text { scores(A) }\end{array}$} & \multirow{2}{*}{$\begin{array}{l}\text { formative, } \\
\text { style paper } \\
\text {-and-pencil } \\
\text { (writing) }\end{array}$} & \multirow{2}{*}{$\begin{array}{l}\text { cumulative } \\
\text { Evaluation: } \\
\text { Of(scor:20) }\end{array}$} \\
\hline & & & & & \\
\hline 1 & $\mathrm{R}-\mathrm{W}$ & 316 & 13.33 & 14.17 & 15.25 \\
\hline 2 & M-_A & 280 & 20 & 17.5 & 19.75 \\
\hline 3 & M-P & 285 & 20 & 16.67 & 19.25 \\
\hline 4 & S-Z & 297 & 18.33 & 15 & 12.25 \\
\hline 5 & M-S & 300 & 13.33 & 11.67 & 8 \\
\hline 6 & M-_D & 292 & 11.17 & 10 & 7.5 \\
\hline 7 & M-_A & 290 & 18.33 & 20 & 16.75 \\
\hline 8 & Z-H & 287 & 14.17 & 15 & 10.75 \\
\hline 9 & $\mathrm{~F}$-_P & 283 & 13.33 & 11.67 & 10.5 \\
\hline 10 & M_-B & 281 & 10 & 10 & 11 \\
\hline 11 & F-P & 284 & 15 & 10 & 10.5 \\
\hline 12 & F-SH & 301 & 13.33 & 13.33 & 10 \\
\hline 13 & Z-_SH & 302 & 6.67 & 10 & 10 \\
\hline 14 & A-A & 402 & 15.83 & 13.33 & 10.25 \\
\hline 15 & $A-F$ & 305 & 13.33 & 14.17 & 11.25 \\
\hline 16 & G-_F & 306 & 13.33 & 11.67 & 6.5 \\
\hline 17 & $\overline{M-M}$ & 730 & 11.17 & 12.5 & 10.5 \\
\hline 18 & R-M & 309 & 18.33 & 15 & 16 \\
\hline 19 & S-M & 312 & 16.17 & 15.83 & 12 \\
\hline 20 & SH-F & 314 & 20 & 17.5 & 16.25 \\
\hline 21 & F-F & 297 & 18.33 & 13.33 & 15.75 \\
\hline 22 & M-N & 313 & 20 & 18.33 & 12.75 \\
\hline 23 & $\mathrm{~K}-\mathrm{H}$ & 293 & 16.17 & 13.33 & 15.5 \\
\hline \multirow[t]{3}{*}{------ } & ---- & ------ & ------------ & '------------- & --------------- \\
\hline & & & $\mathrm{M}=15.21$ & $\mathrm{M}=13.91$ & $\mathrm{M}=12.53$ \\
\hline & & & $\mathrm{S}=3.62$ & $S=2.84$ & $S=3.616$ \\
\hline
\end{tabular}

Table (1) shows the pre-test scores, the developmental and the ductility of the control group. The mean Scores of constellations are 12.53, developmental 13.91 and pre-test scores are 15.21

Table (2) results of the paired-sample t-test for control

\begin{tabular}{|c|c|c|c|c|c|}
\multicolumn{5}{|c|}{ group } \\
\hline $\mathbf{p}$ & df & $t$ & $\begin{array}{c}\text { Standard } \\
\text { deviation(S) }\end{array}$ & Mean(M) & \\
\hline .000 & 22 & -4.689 & 3.618 & 15.2 & pre-test \\
\cline { 4 - 6 } & & & 3.616 & 12.53 & cumulative \\
\cline { 4 - 6 } & & & & & \\
\hline
\end{tabular}

Table (2) shows the results of the paired-sample t-test in the control class, with a degree of freedom of $22 \%$ at the

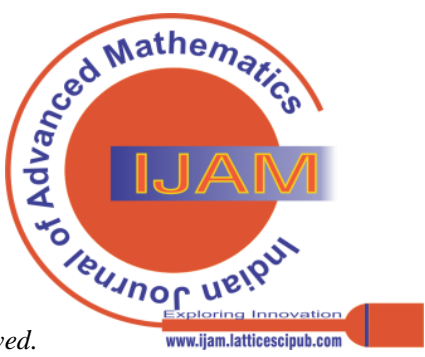


$5 \%$ level $(p=.00)$ equivalent to-4.689 .This value is Greater than table t (2.074), so the null hypothesis is rejected. We find the level of learning increased in the control group. For both experimental and control groups, the dependent

$$
t=\frac{\Sigma D}{\sqrt{\frac{\sqrt{[}\left[\Sigma D^{2}\right]-(x D)^{2}}{\mathrm{~N}-1}}} \text { ) }
$$

T-test $\sqrt{\frac{N\left(x D^{2}-(x)^{2}\right.}{N-1}}$ ) was used to compare the
eans and the null hypothesis evaluation. Also, $t$ is used for merged averages, meaningfully.
Representative of Group 3 was elected under code 219. That answered all 3 questions as shown with TTT219 in table 3. The representative of the other group, which was selected as the Group 1 draw and Barcode 201, answered 2 questions correctly and one incorrect answer and is shown in the table with FTT 201. So the second week, the third week, the sixth week is done. The results are in table (3). True (T) \&False (F);

\subsection{Class B Performance (Experiment)}

\section{Answer the Question (1)}

After 6 weeks of teaching, the seventh week, the oral Question was asked. By lottery, in the first week, the

Table (3) 6-week question status and results

\begin{tabular}{|c|c|c|c|c|c|c|c|c|c|}
\hline $\begin{array}{l}\text { Group } \\
\text { score }\end{array}$ & $\begin{array}{l}\text { Sixth } \\
\text { week }\end{array}$ & Week five & forth week & $\begin{array}{l}\text { Third } \\
\text { week }\end{array}$ & $\begin{array}{c}\text { second } \\
\text { week }\end{array}$ & $\begin{array}{c}\text { The first } \\
\text { week }\end{array}$ & $\begin{array}{c}\text { Code } \\
\text { team } \\
\text { leader }\end{array}$ & $\begin{array}{c}\text { Group members } \\
\text { code, which they are } \\
\text { asked }\end{array}$ & $\underset{\text { number }}{\text { Group }}$ \\
\hline 6 & - & 211:TTT & -- & --- & --- & 219:TTT & 190 & $219-213-190-211$ & 1 \\
\hline 4 & -- & --- & 195:TTT & $\begin{array}{c}\text { 207:FF } \\
\mathrm{T}\end{array}$ & ---- & -- & 195 & 207-210-195-208- & 2 \\
\hline 5 & -- & --- & 206:TTT & --- & ---- & 201:TTF & 215 & 206-201-679-215 & 3 \\
\hline 6 & -- & 212:TTT & ----- & -- & 194 :TTT & --- & 212 & 194-222-193-216 & 4 \\
\hline 3 & 216:TTF & --- & ----- & $\begin{array}{c}\text { 192: } \mathrm{FF} \\
\mathrm{T}\end{array}$ & ----- & --- & 216 & 212-220-196-192 & 5 \\
\hline 4 & 188:TTT & --- & --- & -- & FFT:188 & --- & 205 & 205--191-188- & 6 \\
\hline
\end{tabular}

Table( 3 )shows that students scored 4.69 out of 6 on a mean of $78.16 \%$ of the total 6 points.

Table (4) Status of Class B Final Grades during Semester Paired Samples Statistics

\begin{tabular}{|c|c|c|c|c|c|}
\hline NO & $\begin{array}{c}\text { Stands } \\
\text { Name } \\
\text { and } \\
\text { Surname }\end{array}$ & code & $\begin{array}{c}\text { pre-test } \\
\text { scores(B) }\end{array}$ & $\begin{array}{c}\text { formative } \\
\text { Oral } \\
\text { questions }\end{array}$ & $\begin{array}{c}\text { cumulative } \\
\text { Evaluation: } \\
\text { Of(scor:20) }\end{array}$ \\
\hline 1 & A-N & 219 & 13.33 & 20 & 16.5 \\
\hline 2 & Z-K & 213 & 11.17 & 20 & 16.25 \\
\hline 3 & F-Gh & 211 & 13.33 & 20 & 17 \\
\hline 4 & A-F & 208 & 12.5 & 13.33 & 11 \\
\hline 5 & S-A & 207 & 17.5 & 13.33 & 14 \\
\hline 6 & S-F & 210 & 14.17 & 13.33 & 12 \\
\hline 7 & S-S & 206 & 10 & 16.67 & 12.5 \\
\hline 8 & P-S & 201 & 16.17 & 16.67 & 18 \\
\hline 9 & K-B & 679 & 14.17 & 16.67 & 17.5 \\
\hline 10 & J-S & 215 & 18.33 & 16.67 & 17.5 \\
\hline 11 & M-M & 205 & 17.5 & 13.33 & 16.5 \\
\hline 12 & J-S & 194 & 12.5 & 20 & 13.75 \\
\hline 13 & P-B & 222 & 11.17 & 20 & 13.75 \\
\hline 14 & A-A & 193 & 12.5 & 20 & 14.5 \\
\hline 15 & F-A & 191 & 11.17 & 13.33 & 17.25 \\
\hline 16 & M-GH & 212 & 18.33 & 10 & 17 \\
\hline 17 & F-M & 216 & 19.17 & 20 & 19.5 \\
\hline 18 & M-Y & 220 & 14.17 & 10 & 16.75 \\
\hline 19 & F-B & 195 & 17.5 & 13.33 & 18 \\
\hline 20 & S-T & 196 & 14.17 & 10 & 15.5 \\
\hline 21 & S-A & 190 & 20 & 20 & 20 \\
\hline 22 & Z-A & 192 & 16.17 & 10 & 16.5 \\
\hline 23 & M-A & 188 & 16.17 & 13.33 & 17.25 \\
\hline--- & ----- & ---- & $---------~$ & ------- & -- \\
\hline & & & M=14.83 & M=15.65 & M =16.2 \\
\hline
\end{tabular}

\begin{tabular}{|l|l|l|l|l}
\hline & & & $S=2.88$ \\
\hline
\end{tabular}

$\mathrm{S}=3.82$

$S=2.307$

Table (4) shows the performance of Experiment Class (B). The averages of the cumulative evaluation scores are 16.02 and verbal formulation $\mathbf{1 5 . 6 5}$ and pre-test 14.73 .

Table (5) results of the paired-sample t-test for examination Group(B)

\begin{tabular}{|c|c|c|c|c|c|}
\hline $\mathbf{p}$ & $\mathbf{d ~ f}$ & $\mathrm{t}$ & $\mathrm{S}$ & $\mathrm{M}$ & test \\
\hline .023. & 22 & 2.443 & 2.88 & 14.83 & pre-test \\
\cline { 4 - 6 } & & & 2.307 & 16.02 & cumulative \\
\hline
\end{tabular}

Table (5) shows that the results of the paired-sample t-test for examination Group value of test-dependent t-test, with a degree of freedom 22 at $5 \%$ level ( $p=/ 023$ equals 2.443 ) is greater than table $\mathrm{t}$ (2.074), so the null hypothesis is rejected. With 95\% confidence, we conclude that the new formative, participatory and verbal guided formative assessment has increased the learning of the students in the experimental group,

\section{Answer the Question (2).}

In cumulative Evaluation (end of semester) in the math lesson, in the new method, the experimental group performs better than the control group. 
Table (6) shows the performance of the two groups, based on indicators

\begin{tabular}{|l|l|l|l|l|l|l|}
\hline group- & \multicolumn{2}{|l|}{ Control group A } & \multicolumn{2}{l|}{ B Examination Group } \\
\hline Index & pre-test(A) & $\begin{array}{l}\text { Formative } \\
\text { (A) } \\
\text { written }\end{array}$ & $\begin{array}{l}\text { cumulative } \\
\text { Evaluation(A) }\end{array}$ & pre-test (B) & $\begin{array}{l}\text { Formative } \\
\text { Oral (B) }\end{array}$ & $\begin{array}{l}\text { cumulative } \\
\text { Evaluation(B) }\end{array}$ \\
\hline mean(M) & 15.2 & 13.91 & 12.53 & 14.83 & 15.65 & 16.02 \\
\hline $\begin{array}{l}\text { Standard } \\
\text { deviation(S) }\end{array}$ & 3.62 & 2.84 & 3.616 & 2.88 & 3.82 & 2.307 \\
\hline
\end{tabular}

Table (6) shows the students' academic performance in the two classes of Web A. The mean cumulative scores in Experiment (B) were 16.02, which increased by 1.19, which was 2.67 compared with the mean of group A, which was 12.53 , compared to the pre-test. So we conclude, Group B has made more progress. . On the one hand, the pre-test scores of group A (control) were 15. 2, while the mean pre-test scores of group B were 14.73

Also, the end of semester B test, with a grade point average of 16.02 is higher than that of students with a pre-test score of 14.73 .

$$
E S=\frac{M_{E}-M_{C}}{s_{C}}=\frac{16.02-12.53}{3.62}=/ 96
$$

In this paper, the size of the work is used to aid interpretation. The effect size index is useful for judging the practical significance of research results (Gall et al., 2003: 330).

Effect size is equal to difference between control and experimental groups, divided by standard deviation of control group (Gall et al. $\mathbf{E S}=\frac{\boldsymbol{M}_{E}-M_{C}}{\left(S_{C}\right)}$ (Delaware 2005, p. 395)

\section{Es : Effect size}

Mean experimental group : ME

Mean experimental group : Mc

Standard deviation of control group: SC

The area below the ES curve is about 96. Equals 8315 /. This means that the members of the experimental group, on which the oral developmental test was administered, scored 83.15\% more than the control group. By interpretation, this effect size is very high. However, the experimental group scores at baseline were lower than the control group in terms of mean and effect size.

B) For the control group: Since $t$ (4.787) is greater than t-table (2.074), with a freedom of 22 and a 5\% level, so the null hypothesis is rejected, we conclude that the evaluation method is in written form (midterm to Classic style), with the pre-test scores mentioned, increased in the learning in the control group. Since both groups, the null hypothesis is rejected. Therefore, the effect size was used to measure performance.

The larger effect size indicates a greater difference between the two groups.

\section{Answer the Question (3).}

Is there a significant difference between the two groups before and after the teaching method?

Are there any significant differences between the two groups after the procedure?

(Shivelson.1988 \& Cohen,2001)

When the volume of the sample is equal, it is calculated from the formula $t$ ( Integrated variance.)

$$
\begin{aligned}
& t=\frac{\overline{x_{1}}-\overline{x_{2}}}{\sqrt{\frac{S^{1}{ }_{1}+S^{2}{ }_{2}}{n}}} \\
& t_{\overline{x_{1}}-\overline{x_{2}}}=\sqrt{\frac{S_{1}^{1}+S^{2} 2}{n}}=\sqrt{\frac{10.94+13.08}{23}}=\frac{3.49}{1.04}=3.558
\end{aligned}
$$

Since the obtained $t$ (3.558) is greater than the critical t of the table (2.306) with the degree of freedom, 8 is at the $5 \%$ level. Therefore, we conclude that there is a significant difference between the mean of the mathematical scores at the end of the two semesters.

\section{DISCUSSION AND CONCLUSION}

The purpose of this study was to evaluate the effect of formative (mid-term) evaluative, participatory, and guided oral on math lessons. For this purpose, two groups of students were randomly selected from the Faculty of Computer Science at Guilan University of Technology by Dr. Moein Rasht. One group as control and the other as experiment were randomly selected. In both groups, the math reserves were pre-tested with the same question. From control group A, after 6 weeks of teaching, the written midterm exam was taken in the classical way. But the experimental group participated in 6 weeks of participatory and purposeful oral questioning. There were four designated groups that had to work together

All groups were selected with equal indices, such as the pre-test score, and so on. Only one member of the group was asked to draw a query. And for the next question, the new lesson volume was added to the previous one. And again, by the order of a group, one person was also questioned. The same member could have been elected. Therefore, all members of the group had the same responsibility, and thus the same score. The pre-test scores of the experimental group were lower than the control group scores. But in cumulative evaluation, the experimental group scores were higher than the control group scores. The findings of this experimental study indicate that the larger effect size indicates a greater difference between the two groups, so that group B, which was tested by oral questioning, performed better than the control group.Therefore, the results of this research, Confirms the objective of participatory learning, mathematics lesson, and formative evaluation in oral question. In addition to research by Slavin and Cole-John on learning mathematics in a participatory manner, and research by Rashid Yaghoubi and Kurdi, in examining, comparing,

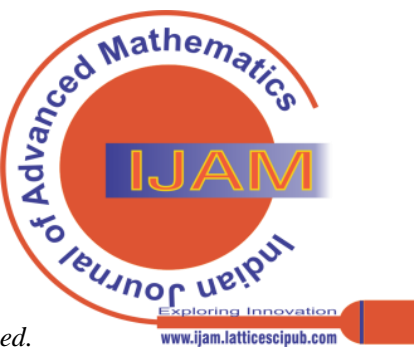


confirms the impact of how a class verbal question arises on learning a mathematical lesson. And by doing research, by Vaezfar, by colleagues, Which illustrates the method of targeted questions on mathematical performance, And the components of understanding, Critical Thinking, And reflective thinking, It is effective, It's the same direction.

\section{REFERENCES}

1. Cur linger, F. A. (1374). Fundamentals of Research in Behavioral Sciences, (Hassan Pasha Sharifi \& Jafaranjafi Zand, Translators).

2. Pasha Sharifi. H, Kiamnesh. A, (1996) Methods of Evaluating Students' Learnings, Ministry of Education.

3. George polya.(2001). Math Creativity. Translated by Parviz. S. Sixth Edition. Tehran: Tatami Press.

4. Shabani . H. (1993) Educational Skills, Post Office.

5. Lotfabadi .H (1995) (Measurement and Measurement in Educational and Psychological Sciences), Hakim Ferdowsi Publications.

6. Alamolhodaei. S. H (2002) New Strategies in Mathematics Education, Method of Publication.

7. Seif, A. A. (2001) Educational Measurement and Evaluation Methods.

8. Jahanshahi. M. (2001). Principles of Learning, and Mathematics Education, High School, Pre-University. School publications.

9. Vaezfar. S.M..F, M A. S . \&.N. M. (2014) Scientific Journal Management System, 2014. Volume 3 Number 2 Page 240-250.

10. Safavid.A (2005). Summary of methods and techniques of teaching contemporary publishing.

11. Hedayatpanah. S .A. (2014) How to teach the Sea of Knowledge Publications.

12. Keramati, M. R. (2005). Collaborative Learning, Motivational Publications - Ansar Publications.

13. Delavare. A. (2011) Probably Practical Statistics in Educational Psychology and Developmental Science.

14. Delavare.,A. (2005) Theoretical and Practical Principles of Research in Human and Social Science.

15. Newman, W. L (2010). Quantitative and qualitative approaches (Hassan. D \& Hossein. K, Translators). Publisher, the Gilded Book Institute (1) and (2). (Date of Issue Volume 2, 2015). (Published in Original Language, 2006).

16. Walpole, R..E (2010). Introduction to Probability and Applied Statistics. (Zahiboun \& m B .G. Aria Nejad, Translators). University of Science and Technology. Eighteenth Edition (Published in Original Language, 2013).

17. Mc.Nab, David E. (2011). Quantitative and qualitative research methods in government management and non-profit organizations. (Reza. V\& M. Sadegh .T, translators). Saffar Publications (Original language publication, 2008).

18. Gaul. M. W \&,J .G (2005). Quantitative and Qualitative Research Methods in Educational Sciences and Psychology. (A. R. Nasr et al., Translators). Publications of Shahid Beheshti University and Jalal (1) and (2). (Date of Issue Volume 2, 2007) (Published in Original Language, 1979).

19. Cohen. L. Michelle .H. (2001). Statistics in Physical Education and Physical Education (A. Delaware, Translator). Allameh Tabataba'i University Press. (Published in Original Language, 2001).

20. Richard J. Shavelson. (2000). Statistical Reasoning in the Behavioral Sciences (A. Kiamenesh. Translator). Institute for Academic Jihad Publications (Published in Original Language, 2010).

21. David. A.\& D.. W. (2015). Survey in Social Research. (H. Nayebi, Translator) Tehran, Ney, 12th Edition, p. 84 (Original Language Publication, 2014).

22. David, R, B\& F. Design of Experiments and Statistical Methods. (Talebi\& Mousavi, Translators). Post-Graduate Publications (Published in Original Language, 1995).

23. Chava .F\& D .N (2011). Research Methods in Social Science (Larijani \& Fazeli, Translators). Soroush Publications (Published in Original Language, 1976).

24. John .F (2012) Mathematical Statistics. (A. Amidi \& M .Q Vahidi Asl, translators). University Publication Center. (Published in Original Language, 2005).

25. Levin. R, I, \& David. S. R. (1387). Statistics for management. (Abbas Saleh and M.R Saadi, translators). Publisher: Etihad - New World. (Original language publication, 1998).

26. Quarterly Journal of Educational Psychology F 7th No. 22, Sina, Hamedan
27. Shivelson . R (1988) Richard. Statistical reasoning for the Behaviora Sciences. Translated br: A.R. Kiamanesh. Published in Allameh Tabataba'i University Press. 2015).

\section{AUTHORS PROFILE}

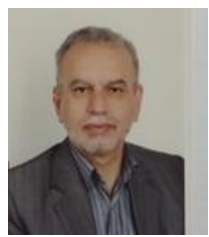

Specifications

Name: Ahmad

- Last name: HyatPanah Shaldehi

Place of birth: 1957,Iran, Gilman

-- Field of study: Mathematics (diploma to doctorate)

- - Skills and interest: Statistics and research methods in

the behavioral sciences of chord and

-- Teaching: 44 years (university and education)

Researches:

- Conductor of various researches: 32 cases

Published books: 15 items, like:

- Cognitive Style (FI\&FD) Mathematical According Bloom's Taxonomy

,Publisher (lap) in Germany

-General Mathematics(1):ISBN : 978-964-9592-82-4 Publisher : Daryaye

Danesh

- General Mathematics(2):ISBN : 978-964-6977-39-1 Publisher : Abrang

- How we research? ISBN :978-964-9592-85-5 Publisher : Daryaye danesh

- Statistics and Probability ISBN: 978-964-95928-3-1 Publisher Daryaye danesh

-Pre Mathematics . ISBN : 978-964-9592-84-8 Publisher : Daryaye danesh -Why learn math? ISBN : 964-6677-12-x : Publisher : Abrang danesh Awards, 47 items, like:

1. The Best researcher Iranian 2012

2. The best University2012 of superior technical and professional Researchers

3) The Best University2013 of superior technical and professional Researchers

(4 The Best researcher Iranian (Guilan) 2012

(5TheBest researcher Iranian (Guilan) 2013

6) The Sample Teacher Iranian 2003

7) The Sample Teacher Iranian 2006

8) The Sample Teacher Iranian 2012

9) Author of the article Top in Iran2000

10) Author of the article Top in Iran 2004

11) Author of the book Top Iran 2019

12) Author of the book Top Iran 2018

13) Author of the book Top Iran ,...

- Workshop: 48 items

Judging articles:

: Over 1300 cases (provincial, national and international)

Articles: like

Presenting papers in national and international conferences: 51 cases

-- Published articles: 99 cases in Iran and 23 cases outside

Iran

1.Fuzzy approach to Likert Spectrum in Classified levels in Surveing research

A hedayatpanah

The Journal of Mathematics and Computer Science 2 (2), 394-401 2011 2.Study and investigation of the problems and learning disorders of students by various cognitive styles in mathematics course at Rasht shahid chamran higher education center

The Journal of Mathematics and Computer Science 1 (3), 216-229 2010

3.Using Eta $(\eta)$ correlation ratio in analyzing strongly nonlinear relationship between two Variables in Practical researches

AH Shaldehi

Journal of mathematics and computer science(tjmcs) 7 (3), 213-220 2013

4.Students' Field-dependency and Their Mathematical Performance based on Bloom's Cognitive Levels

R farhad, Alamolhodaei Hassan, hedayatpanah Ahmad

Korean Society of Mathematical Education 15 (4), 373-386

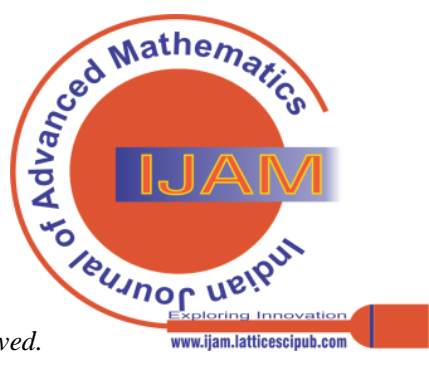

